\title{
Steriles Anbringen des unsterilen PDD-Lichtkabels an eine Optik
}

Wie ein PDD-Lichtkabel für die photodynamische Diagnostik ohne Kontamination mit dem sterilen Zystoskop verbunden werden kann, erklären Ihnen unsere Autoren in folgendem Tipp.

Das PDD-Lichtkabel für die photodynamische Diagnostik ist entgegen anderen Lichtkabeln aus technischen Gründen nicht sterilisierbar. Als Provisorium wird es auf das steril eingebrachte Zystoskop nach Absprühen mit einem alkoholischen Desinfektionsmittel mit dem Schaft konnektiert.

Hier hilft ein einfacher Trick: Wird der Kamerabezug nicht wie üblich hinter, sondern vor dem Lichtkabelansatz auf die Optik geklebt, kann nicht nur die Kamera, sondern auch das Lichtkabel durch den Springer im Kamerabezug angeschlossen werden. Nachdem der Kamerabezug über beide Elemente gezogen wurde, sind keine Kontaminationen mehr zu befürchten.

Karsten Eisenblätter,

PD Dr. Andreas Wiedemann

\section{Korrespondenz:}

PD Dr. Andreas Wiedemann

Urologische Klinik

Evangelisches Krankenhaus

im Diakoniewerk Ruhr gGmbH

Lehrstuhl für Geriatrie

der Universität Witten/Herdecke

Pferdebachstr. 27

58455 Witten

Tel.: +49/2302/175-2521

awiedemann@diakonie-ruhr.de

Interessenkonflikte: PD Dr. Wiedemann: Beratungstätigkeit: Dr. Pfleger, Pfizer; Vortragstätigkeit: Allergan, AMS Deutschland, Astellas, Berlin-Chemie, Jansen, Lilly Deutschland, Dr. Pfleger, Pfizer, PohlBoskamp; Studienfinanzierung: AMS Deutschland

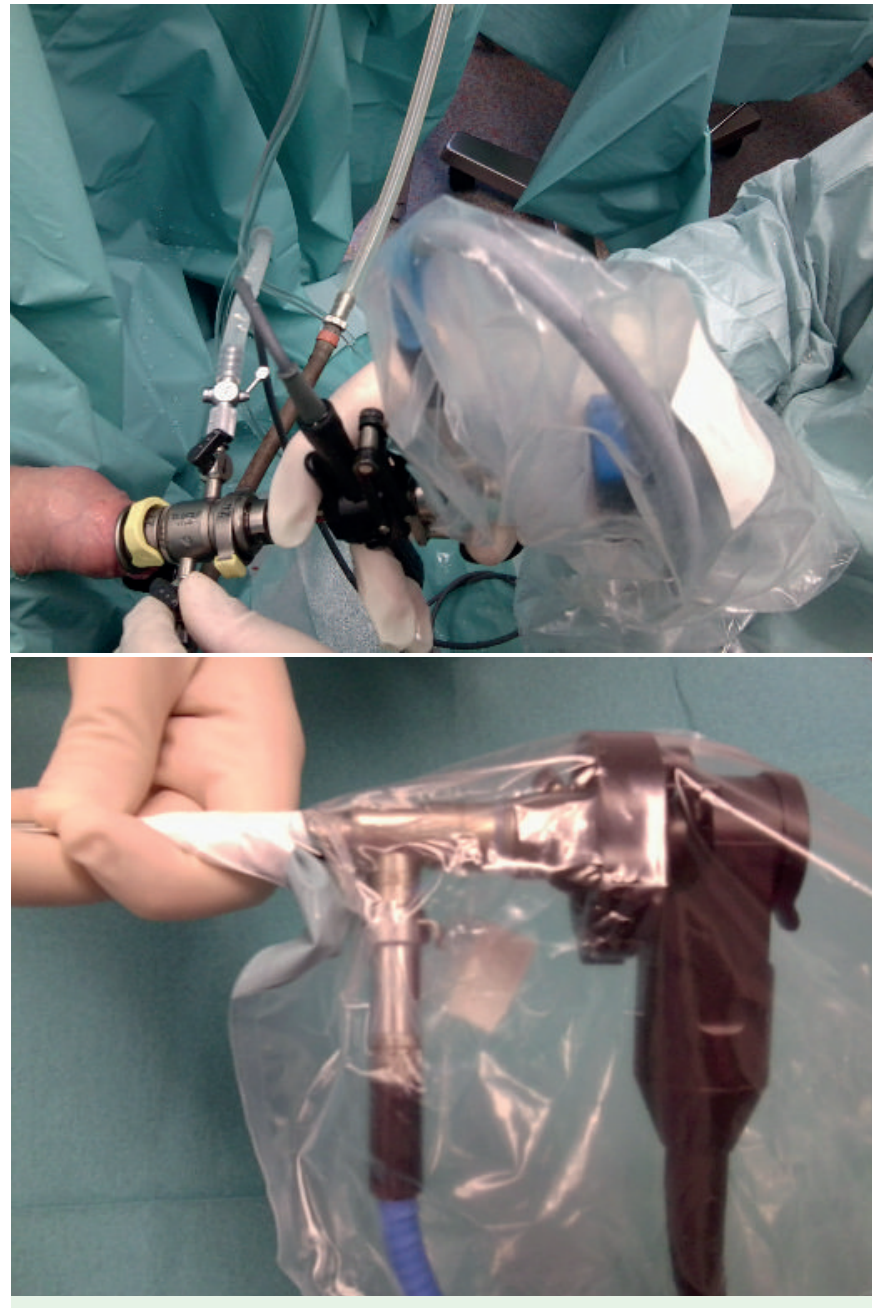

PDD-Kabel im Kamerabezug 